\title{
EXPERIMENTAL ANALYSIS AND OPTIMIZATION OF MATERIAL CONSUMPTION
}

\author{
Kushal G. Ambli \\ VSM Institute of Technology, Nipani
}

\begin{abstract}
Foundry is one of the most Energy intensive metallurgical industries. The major part of the energy consumed in Foundry is in the melting units. Energy also contributes to the major cost input to the production of castings. Besides its, high energy consumption is upbringing the threat of climate change and global warming. Therefore it becomes very much necessary to look into various means by which energy consumption in melting units can be minimized considerably. Much of the work is being done by many Foundry men to reduce specific energy consumption in liquid metal preparation. Operational uncertainties create disincentives for use of recycled materials in metal production. One that greatly influences remelter batch optimization is variation in the raw material composition, particularly for secondary materials. Currently, to accommodate compositional variation, firms commonly set production targets well inside the window of compositional specification required for performance reasons.
\end{abstract}

$* * *$

\section{INTRODUCTION}

The present work deals with some of the steps taken at JPF Metacast, Belgaum. The Foundry are required to reduce material consumption specially in Medium frequency furnace that include improved, scrap charging sequence, furnace, sampling, changes in metal composition etc. This has resulted in reduction of specific material consumption and significantly monetary savings.

\section{INDUCTION FURNACE METAL} \section{CONSUMPTION}

There are many metals used in one melt of induction furnace, which is around 500kgs. Different composition can be used of metal and its additives to get different grades of metal. JPF Metacast produces mainly three grades of metal, those are SG iron, pulley grade and ordinary grade, which are based on customer requirements.

The table 1 shows different addition of metal to form the required grade. The actual process varies slightly, for the component numbered 620 and 637 the amount of metal melted is around $485 \mathrm{~kg}$, as the metal required for the above mentioned components is around $406 \mathrm{~kg}$. The extra metal is melted due to loss of metal while pouring and melting.

The figure 1 shows the component. There are certain experiments conducted before manufacturing of this component.

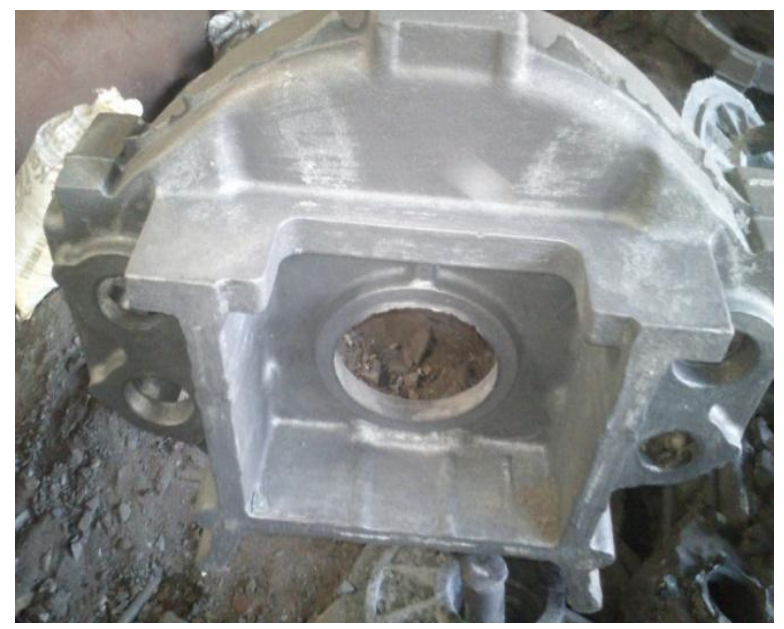

Fig 1 Component 
Table 1 Grade wise metallic mix for $500 \mathrm{~kg}$

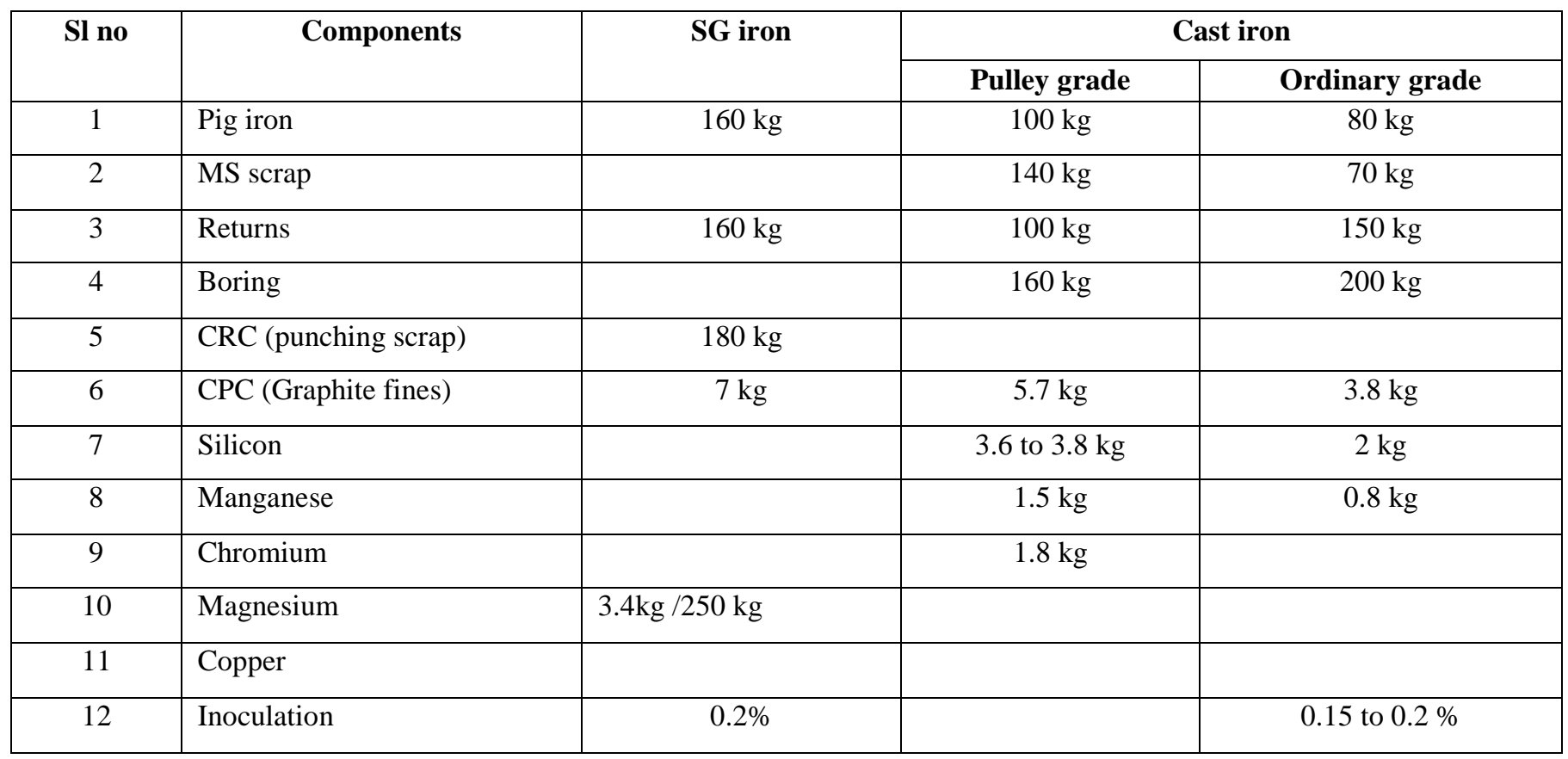

Table 2 Metal consumption with boring

\begin{tabular}{|l|c|c|c|c|c|c|c|c|}
\hline SI no & $\mathbf{1}$ & $\mathbf{2}$ & $\mathbf{3}$ & $\mathbf{4}$ & $\mathbf{5}$ & $\mathbf{6}$ & $\mathbf{7}$ & $\mathbf{8}$ \\
\hline Units & 250 & 256 & 254 & 252 & 255 & 258 & 254 & 258 \\
\hline MS scrap & 140 & 140 & 140 & 140 & 140 & 140 & 140 & 140 \\
\hline Pig iron & 60 & 60 & 60 & 60 & 60 & 60 & 60 & 60 \\
\hline Boring & 200 & 200 & 200 & 200 & 200 & 200 & 200 & 200 \\
\hline Returns & 70 & 71.5 & 60 & 70 & 70 & 70 & 70 & 70 \\
\hline Additives & 13.72 & 13.72 & 13.72 & 13.72 & 12.32 & 13.72 & 12.32 & 12.32 \\
\hline Total wt & 483.72 & 485.2 & 473.72 & 483.7 & 482.3 & 483.7 & 482.3 & 482.3 \\
\hline Return wt & 13.8 & 14 & 10 & 42 & 35.5 & 0 & 23.9 & 24 \\
\hline Metal wasted & 63.92 & 65.22 & 57.72 & 35.72 & 40.82 & 77.72 & 52.42 & 52.32 \\
\hline Bunch wt & 406 & 406 & 406 & 406 & 406 & 406 & 406 & 406 \\
\hline Burning loss & $\mathbf{1 3 . 2 1 4}$ & $\mathbf{1 3 . 4 4}$ & $\mathbf{1 2 . 1 8 4}$ & $\mathbf{7 . 3 8 4}$ & $\mathbf{8 . 4 6 3}$ & $\mathbf{1 6 . 0 7}$ & $\mathbf{1 0 . 8 7}$ & $\mathbf{1 0 . 8 5}$ \\
\hline
\end{tabular}

The burning loss is calculated by using below mentioned formula. Higher the burning loss more will be the melting losses. These losses also effect the energy consumption of the induction furnace. The graph 1 shows the set of eight readings which shows variation in burning losses. 


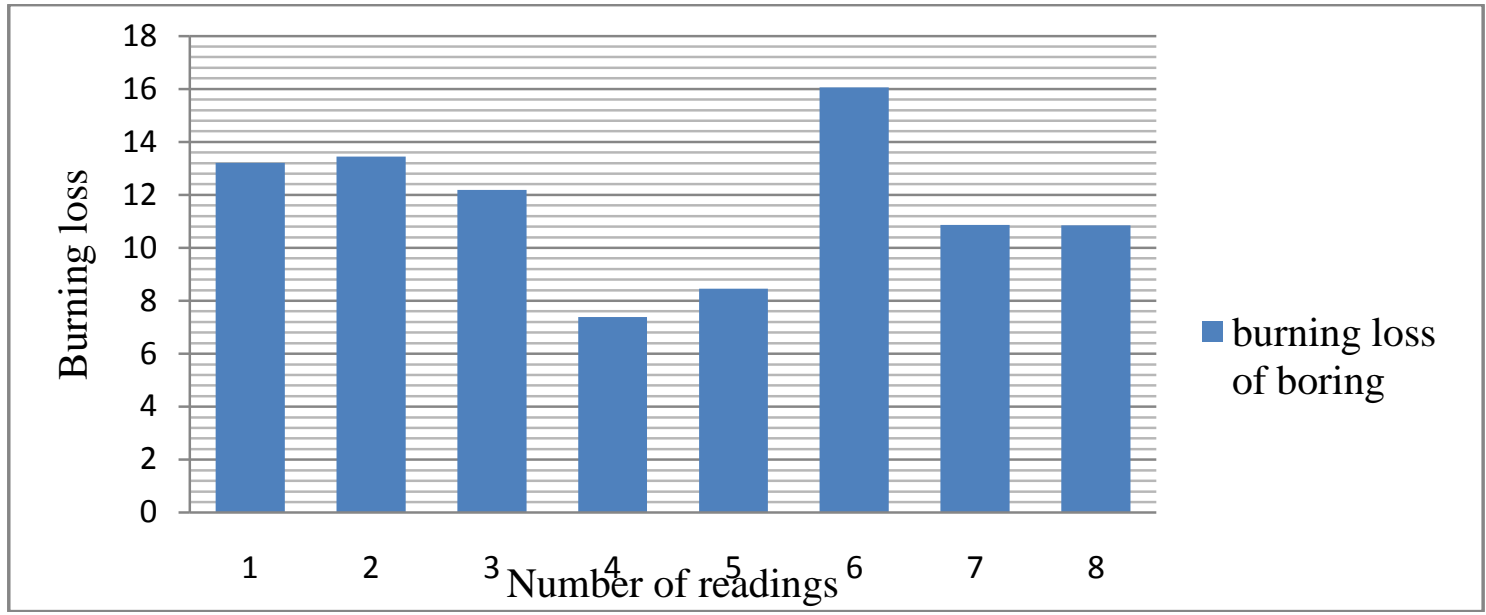

Graph 1 - Burning losses of current process

\subsection{Calculations}

- $\quad$ Total weight $=$ MS scrap + pig iron + boring + returns + additives

- $\quad$ Bunch weight $=$ the bunch weight of each 620 or 637 component is $203 \mathrm{~kg}$

- $\quad$ Metal wasted $=$ Total weight - bunch weight - return metal weight

- $\quad$ Burning losses $=$ metal wasted $/$ total weight of metal $* 100$

- $\quad$ Standard deviation $(\mathrm{s}$ or $\sigma)=$

$s=\sqrt{\frac{1}{N-1} \sum_{i=1}^{N}\left(x_{i}-\bar{x}\right)^{2}}$

$\mathrm{X}=\left(\mathrm{x}_{1}+\mathrm{x}_{2}+\ldots . \mathrm{xn}\right) /(\mathrm{n}-1)$

\subsection{Improvement in Metal Consumption}
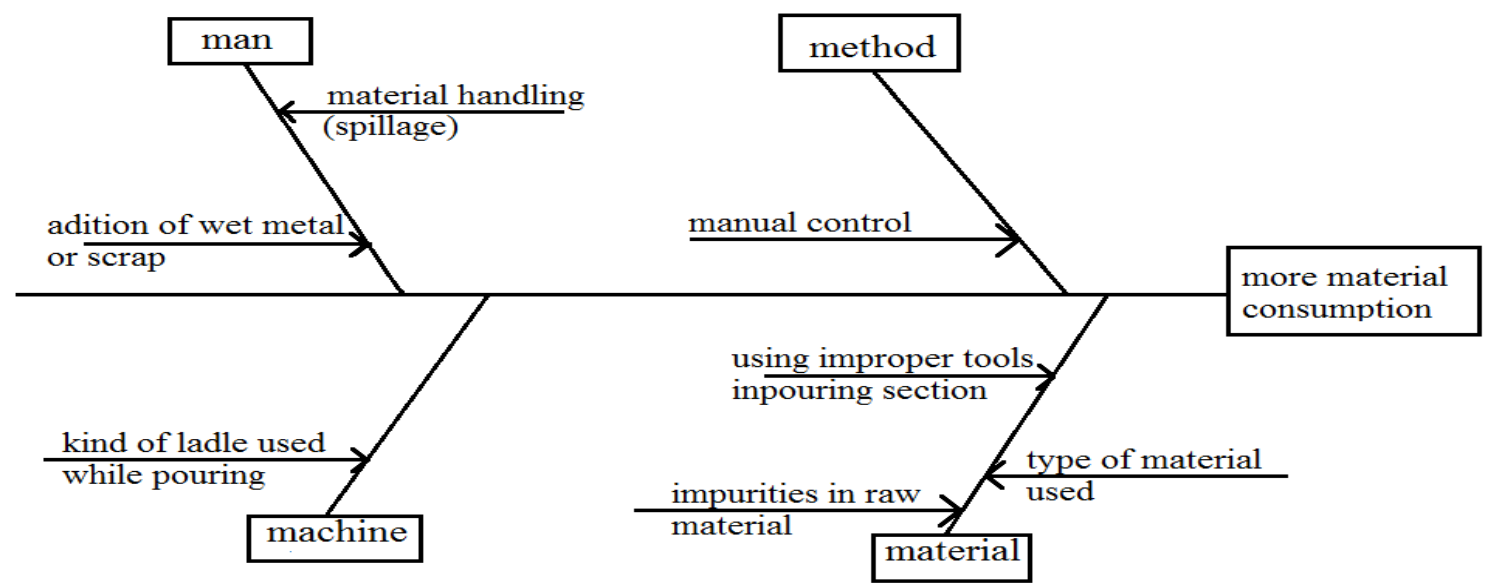
Fig 2 Fish bone diagram (Cause and effect diagram) for material consumption

\section{FIRST EXPERIMENT CONDUCTED ON METAL CONSUMPTION}

In the early process, it was noted that the burning loss of melting was very high. In that process MS scrap, returns and boring were main constituent of the charge melted. Some changes were made in composition of the metal to be melted. Boring was eliminated, and returns were added around $270 \mathrm{~kg}$ for every melt. This change was made because, boring contained many impurities like mud, oil etc. It is difficult to separate mud and other impurities from boring, which also consumes labour hours. Presence of unwanted material in boring also increases the melting loss of the induction furnace. Though boring melts faster than the other metals, presence of impurities in boring increases the time consumed for one melt.

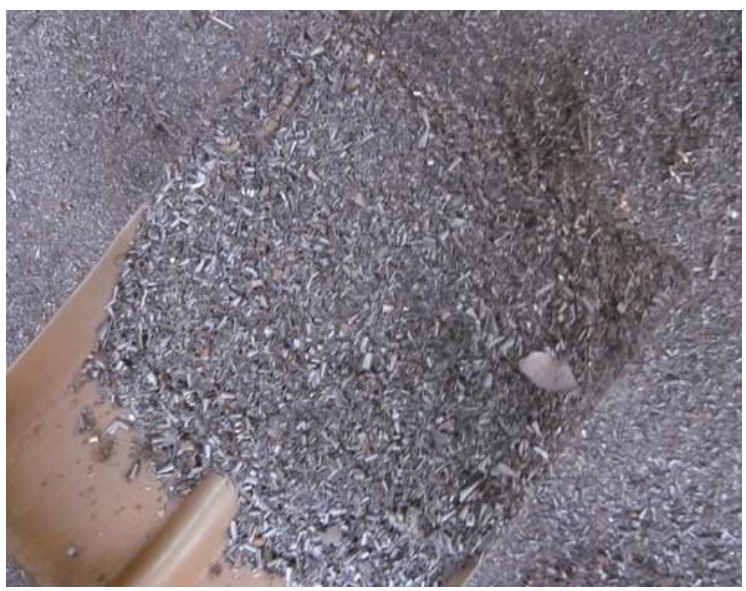

Fig 3 Boring
Figure 3 shows the boring, in this experiment all compositions are kept same except that the boring has been eliminated and is compensated by adding extra returns.

Returns is the metal got from runner, riser and other gating systems; these cannot be used directly for melting, as the return metal contains sand particles adhering to it. The returns extracted from the mould are shot blasted, by using blasting machine. The blasting machine forces a small diametric shots along with high pressured air, which when hits the metal, makes sand and other inclusions to be removed.

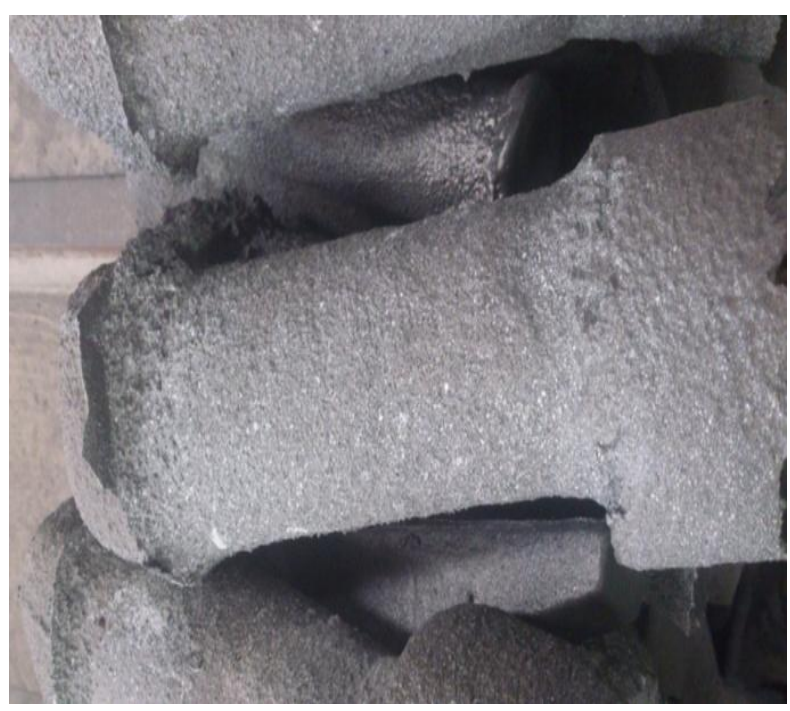

Fig 4 Return metal

Table 3 First composition change

\begin{tabular}{|l|l|l|l|l|l|l|l|l|}
\hline Sl no & 1 & 2 & 3 & 4 & 5 & 6 & 7 & 8 \\
\hline Units & 253 & 254 & 252 & 256 & 251 & 250 & 256 & 258 \\
\hline Ms scrap & 140 & 140 & 140 & 140 & 140 & 140 & 140 & 140 \\
\hline Pig iron & 60 & 60 & 60 & 60 & 60 & 60 & 60 & 60 \\
\hline Returns & 270 & 270 & 270 & 270 & 270 & 270 & 270 & 270 \\
\hline Additives & 12 & 13.82 & 13.82 & 13.82 & 13.82 & 13.82 & 13.72 & 12.32 \\
\hline Total wt & 482 & 483.82 & 483.82 & 483.82 & 483.82 & 483.82 & 483.72 & 482.32 \\
\hline Return wt & 46 & 53.6 & 55 & 53.7 & 45.8 & 56.6 & 42.7 & 46.2 \\
\hline Metal wasted & 30 & 24.22 & 22.82 & 24.12 & 32.02 & 21.22 & 35.02 & 30.12 \\
\hline Bunch wt & 406 & 406 & 406 & 406 & 406 & 406 & 406 & 406 \\
\hline Burning loss & 6.2241 & 5.006 & 4.7166 & 4.9853 & 6.6182 & 4.3859 & 7.2397 & 6.2448 \\
\hline
\end{tabular}


The table 3 shows the composition of the experiment conducted in order to reduce the burning losses to as minimum

as possible

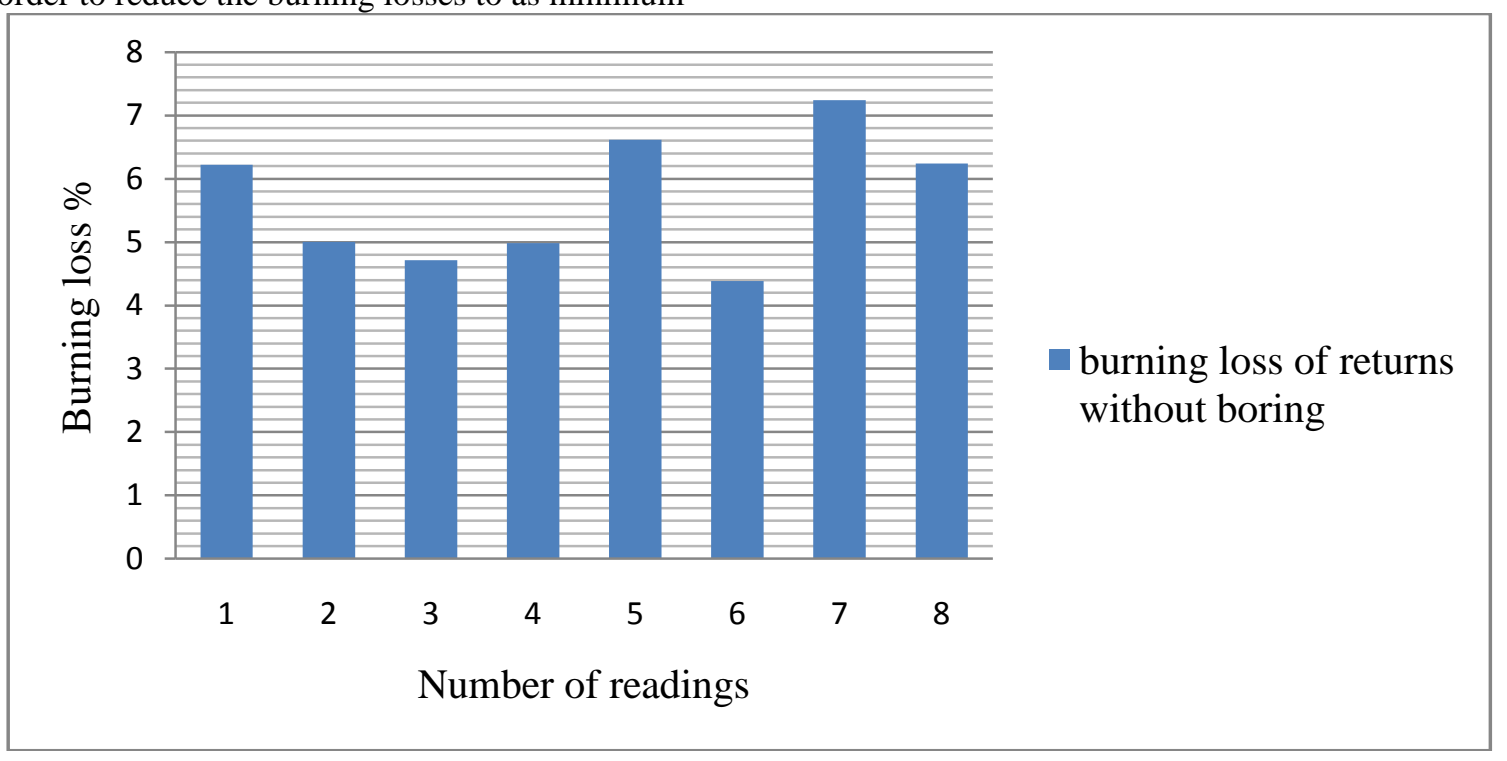

Graph 2 Burning losses without boring

\subsection{Calculation}

- $\quad$ Total weight $=$ MS scrap + pig iron + returns + additives

- $\quad$ Bunch weight $=$ the bunch weight of each 620 or 637 component is $203 \mathrm{~kg}$

- $\quad$ Metal wasted $=$ Total weight - bunch weight - return metal weight

- Burning losses $=$ metal wasted $/$ total weight of metal $* 100$

- $\quad$ Standard deviation $(\mathrm{s}$ or $\sigma)=$

$$
\begin{gathered}
s=\sqrt{\frac{1}{N-1} \sum_{i=1}^{N}\left(x_{i}-\bar{x}\right)^{2}} \\
\mathrm{X}=(\mathrm{x} 1+\mathrm{x} 2+\ldots \mathrm{xn}) /(\mathrm{n}-1)
\end{gathered}
$$

Therefore from equation 1 and 2

$$
X=5.677 \%
$$

From the above mean value, average of $5.677 \%$ of burning loss is developed by sample of eight readings.

$$
\sigma=1.03 \%
$$

The above value shows the deviation of the burning loss from its mean value
That is, from the mean value of $5.677 \%$, there is a \pm variation of $1.03 \%$

By this experiment, it can be seen that the percentage of burning loss has been reduced drastically

\section{SECOND EXPERIMENT CONDUCTED ON METAL CONSUMPTION}

In the first experiment, though the burning losses were reduced to an extent, but still burning losses were high. In the below figure it can be seen that there are sand inclusion in the metal, as the sand has high melting temperature and metal has lower melting point than sand, the sand doesn't melt in the induction furnace and consumes unnecessary electrical energy. 


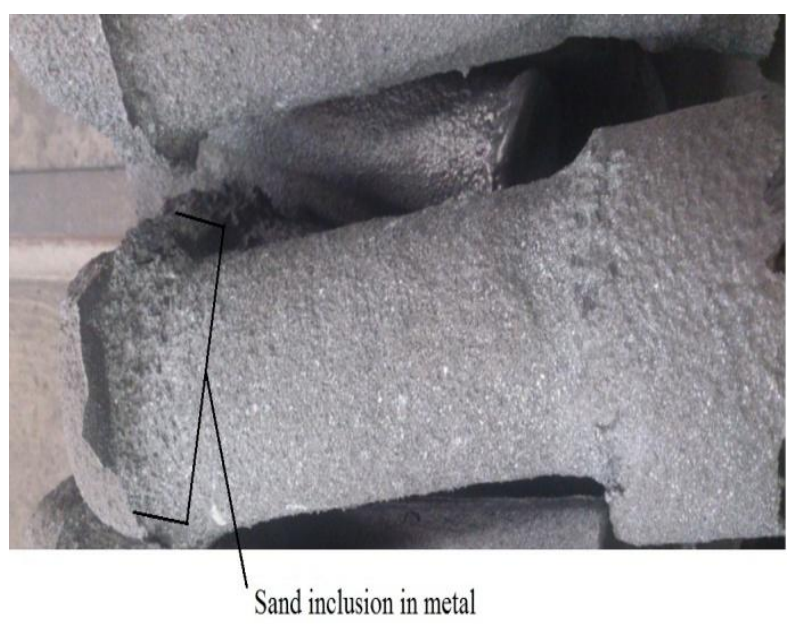

Fig 5 showing sand inclusion in return metal

Shot blasting process is also of no use in removing these sand inclusions. This type of sand inclusion can be reduced by while preparing mould, mould paint is applied for better surface finish, this mould paint can be applied at the riser portion of the mould, so that molten metal remains separated from mould surface this can reduce sand inclusions in metal. The riser portion is rough and uneven. The roughness of the riser portion of the mould should be reduced before the application of mould paint.

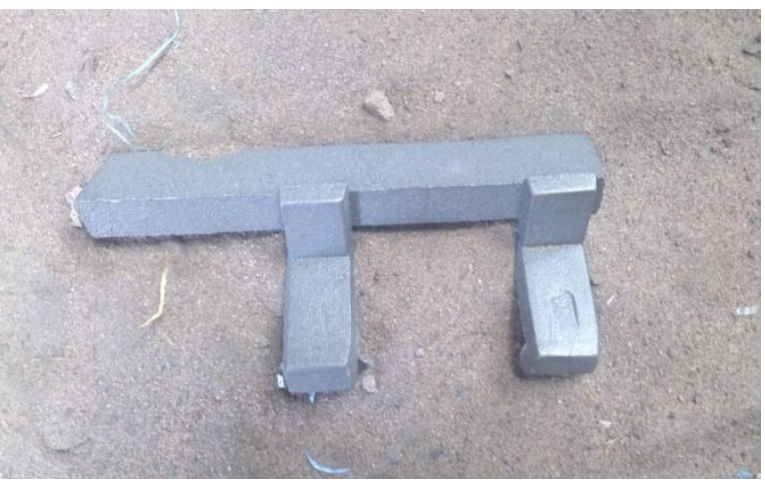

Fig 6 Shell return metal

In this experiment instead of normal returns, shell returns were used. The shell return is almost pure metal with no or very less sand inclusions.

Table 4 Second composition change

\begin{tabular}{|l|l|l|l|l|l|l|l|l|}
\hline Sl no & 1 & 2 & 3 & 4 & 5 & 6 & 7 & 8 \\
\hline Units & 249 & 255 & 253 & 257 & 259 & 253 & 255 & 254 \\
\hline MS scrap & 140 & 140 & 140 & 140 & 140 & 140 & 140 & 140 \\
\hline Pig iron & 60 & 60 & 60 & 60 & 60 & 60 & 60 & 60 \\
\hline Shell returns & 270 & 270 & 270 & 270 & 270 & 270 & 270 & 270 \\
\hline Additives & 13.72 & 12.32 & 12.32 & 13.72 & 13.72 & 13.72 & 12.32 & 13.72 \\
\hline Total wt & 483.72 & 482.32 & 482.32 & 483.72 & 483.72 & 483.72 & 482.32 & 483.72 \\
\hline Return wt & 55.2 & 59.2 & 58.5 & 58.1 & 50.2 & 53.8 & 60 & 56.9 \\
\hline Metal wasted & 22.52 & 17.12 & 17.82 & 19.62 & 27.52 & 23.92 & 16.32 & 20.82 \\
\hline Bunch wt & 406 & 406 & 406 & 406 & 406 & 406 & 406 & 406 \\
\hline Burning loss & 4.6556 & 3.5495 & 3.6946 & 4.0561 & 5.6892 & 4.945 & 3.3836 & 4.3041 \\
\hline
\end{tabular}

The table 4 shows the composition of the experiment conducted in order to reduce the burning losses to as minimum as possible. Shell returns are got from shell casting process, and sand employed in this process is Green sand. As the packing density of the green sand is high compared to $\mathrm{CO} 2$ sand, the casting and returns got from this process are of much better surface finish. Producing castings by using green sand process is slow process, therefore $\mathrm{CO} 2$ process is mainly employed for faster production. 


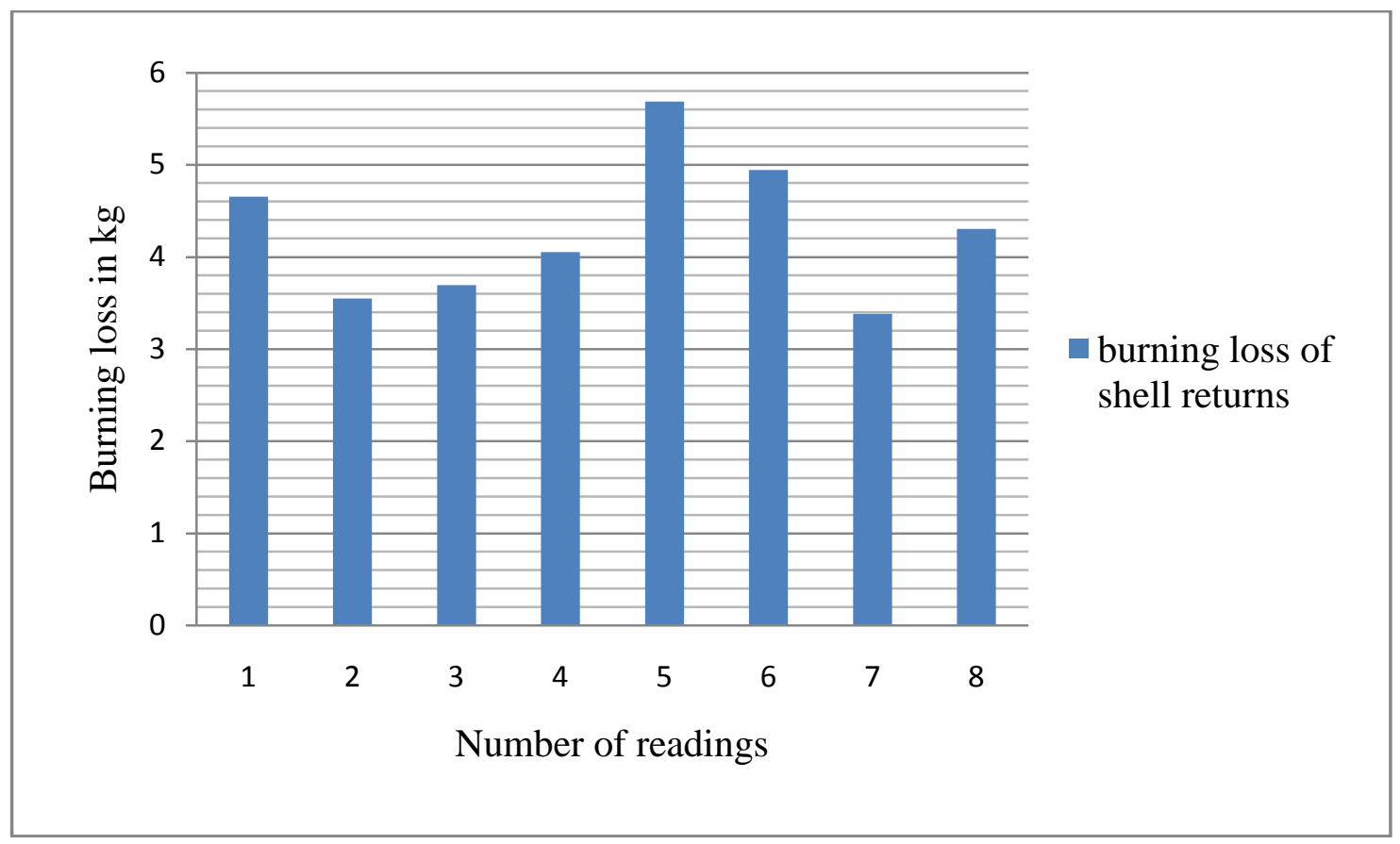

Graph 3 Burning losses with shell returns

\subsection{Calculation}

- $\quad$ Total weight $=$ MS scrap + pig iron + shell returns + additives

- $\quad$ Bunch weight $=$ the bunch weight of each 620 or 637 component is $203 \mathrm{~kg}$

- $\quad$ Metal wasted $=$ Total weight - bunch weight - return metal weight

- $\quad$ Burning losses $=$ metal wasted $/$ total weight of metal $* 100$

- $\quad \operatorname{Standard~deviation}(\sigma)=$

$$
s=\sqrt{\frac{1}{N-1} \sum_{i=1}^{N}\left(x_{i}-\bar{x}\right)^{2}}
$$

$$
\overline{\mathrm{x}}=(\mathrm{x} 1+\mathrm{x} 2+\ldots . \mathrm{xn}) /(\mathrm{n}-1)
$$

There from equation 1 and 2

$\overline{\mathrm{x}}=4.284 \%$

From the above mean value, average of $4.284 \%$ of burning loss is developed by sample of eight readings.

$\sigma=0.78 \%$

The above value shows the deviation of the burning loss from its mean value

That is, from the mean value of $4.284 \%$, there is a \pm variation of $0.78 \%$

By this experiment, it can be seen that the percentage of burning loss has been relatively reduced.

\section{SUMMARY OF METAL CONSUMPTION}

Table 5 Summary of metal consumption

\begin{tabular}{|l|l|l|l|}
\hline & with boring & without boring & with shell RR \\
\hline Average burning loss & $11.56 \%$ & $5.68 \%$ & $4.28 \%$ \\
\hline Standard deviation & $2.80 \%$ & $1.03 \%$ & $0.78 \%$ \\
\hline
\end{tabular}




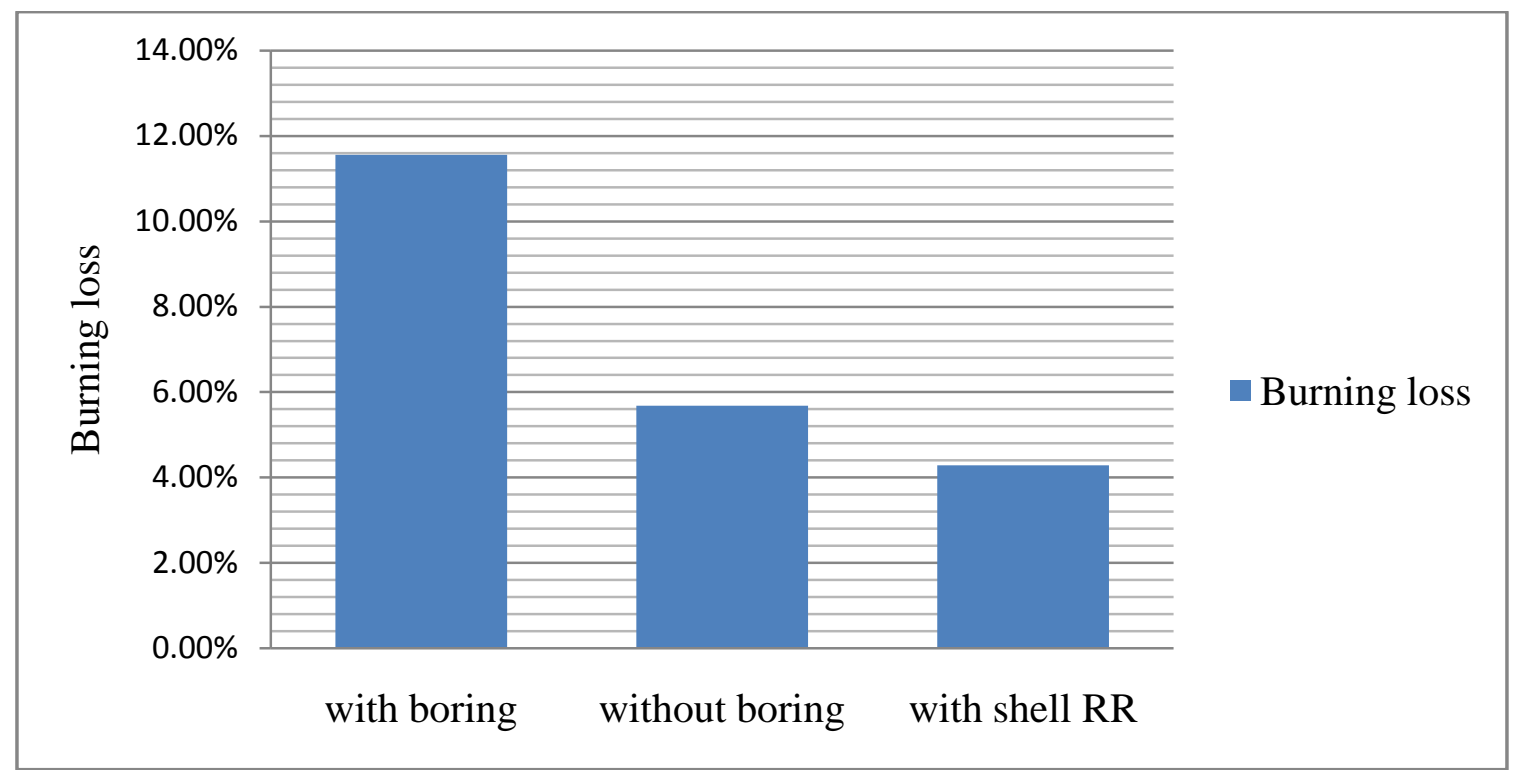

Graph 4 Summary of burning loss

Table 4 and graph 3 shows the relative reduction in burning loss. By the experiments conducted it is possible to reduce the burning losses from an average of $11.56 \%$ to an average of $4.2 \%$.

The limit of burning loss set in JPF Metacast is around $3 \%$. There are other unaccounted loss of metal such as spillage of metal while pouring in to mould and ladle, the wetness of metal and many other factors.

\section{CONCLUSIONS}

- The initial consumption of metal was high. The average burning loss earlier was $11.56 \%$. In the first experiment, the burning loss was reduced to the average of $5.68 \%$. In the second experiment, the burning loss was reduced to $4.28 \%$.

- The burning loss generated now is also high, as the maximum burning loss which is to be got is $3 \%$.

- Different composition of metals can be used without altering the grade of metal, so as to reduce the burning losses to minimum as possible.

- Spillage of metal also incorporates the burning loss, as the burning loss is derived from loss of metal before pouring and after pouring, therefore it is very much necessary to reduce the spillage of metal while it is melted form.

\section{REFERENCES}

[1] Principles of Foundry Technology - P L Jain

[2] Introduction to basic manufacturing process and workshop technology - rajendra simha.

[3] Better Productivity, Metal Quality with Natural Induction Stirring - Keshecki, Robert. Foundry
Management \& Technology. Jan2010, Vol. 138 Issue 1, p12-13.

[4] Saving Electrical Energy in Coreless Induction Furnaces - Williams, D. C. Foundry Management \& Technology. Jan2010, Vol. 138 Issue 1, p13-14.

[5] Improvement in Energy efficiency of melting furnacea case study - Dr D S Padan - Foundry, Tata Motors Ltd. Jamshedpur

[6] Induction Furnace - Vivek R. Gandhewar et al. / International Journal of Engineering and Technology Vol.3 (4), 2011, 277-284

[7] Energy Conservation in Foundry Industry by Modelling and Experimental Investigation of Induction Furnace Process Parameters - International Journal of Current Engineering and Technology, Vol.2, No.3 (Sept. 2012) ISSN 2277 - 4106 